\title{
Survivors' Perspectives of Organizational Downsizing on Knowledge Sharing in a Downsized Environment
}

\author{
Patricia Michelle Hall \\ School of Business, University of Phoenix, Phoenix, USA \\ Email:pmm7@email.phoenix.edu
}

Received October $15^{\text {th }}, 2012$; revised November $18^{\text {th }}, 2012$; accepted November $26^{\text {th }}, 2012$

\begin{abstract}
Organizational workforce reductions can negatively affect a company's ability to preserve its knowledge base. The problem researched in this study was the perceived effect of downsizing on knowledge sharing among surviving employees. The purpose of this study was to determine the perceived effect of downsizing on knowledge sharing. Survivors' knowledge sharing behavior was examined in relation to 1) survivor syndrome, 2) attitude towards knowledge sharing, and 3) perceived loss of knowledge power. A quantitative correlation research design was used to investigate the relationship between downsizing and knowledge sharing. A web-based survey was used to collect data. The convenience sample consisted of 37 management employees in the Texas region of a management consultant organization. Three sets of variables were examined: 1) survivor syndrome and actual knowledge sharing behavior, 2) survivors' attitudes toward knowledge sharing and actual knowledge sharing behavior, and 3) perceived loss of knowledge power and actual knowledge sharing behavior. Findings from a Spearman rank order correlation revealed a statistically significant positive correlation between perceived loss of knowledge power and actual knowledge sharing behavior. Understanding survivors' reactions can assist with planning for future reductions, and lead to the development of training programs to counter the challenges.
\end{abstract}

Keywords: Organizational Change; Knowledge Management; Organizational Behavior; Downsizing, Survivor Syndrome

\section{Introduction}

Numerous organizations across a variety of sectors continue to announce organizational downsizing initiatives, resulting in millions of American workers being laid off annually (Linn, 2012). Henkoff (1994) indicated that "more often than not, one round of downsizing merely leads to another [as] two-thirds of corporations that thin their ranks one year, follow-up with another purge the next" (p. 58). Overcoming the challenges associated with downsizing requires an ideal balancing act. Henkoff (1994) indicated that challenges stem from trying to drive productivity, while operating within the realms of lower gross margins and headcount.

Platt indicated that "there is only so much cutting you can do and still maintain the character and strength of your company" (as cited in Henkoff, 1994: p. 62). As a result, organizational leaders should not "expect a payoff unless [they] do so with a well-thought-out strategy that enables [them] to support [their] survivors" (as cited in Henkoff, 1994: p. 64). Gone are the days of the psychological contract of lifetime employment.

Change continues at the same time that workforces are shrinking. As a result, knowledge management initiatives have become an area of focus to assist with maintaining a competitive advantage. Lesser and Prusak (2001) indicated that initiatives range from "identifying and sharing relevant practices, locating and highlighting expertise, fostering communities of practice and installing collaborative technologies" (p. 101). The challenge; however, stems from the fact that workforce reductions and/or downsizing, can negatively affect an organizations ability to preserve this knowledge base. As a result, "remaining workers faced with new duties may be frustrated and unproduc- tive" (Lesser \& Prusak, 2001: p. 101).

As such, greater emphasis is needed on establishing a solidified knowledge transfer process. Gaining the full buy-in and support of senior leaders will be needed in an effort to foster this type of environment. Appelbaum, Close, and Kasa (1999) indicated that trust erodes, and the credibility of senior managers typically drops by an estimated 35\% after restructuring occurs. As a result, employees who are concerned about their current jobs, or who are faced with uncertainty, anxiety, or doubts regarding how they will fit in and/or be perceived within the newly restructured organization, may actually steer the organizational culture towards becoming a culture of knowledge hoarding in lieu of knowledge sharing (Davenport \& Prusak, 2000).

Rubenstein and Geisler (2003) indicated that a common mindset that surfaces within restructured organizations, seems to be a culture that embraces an ideal that knowledge is power. As a result, unless specifically asked, information is typically not freely or willingly shared. Working within an environment where information is hoarded or where one feels that every source of information is privileged, or can only be obtained on a need-to-know basis can obstruct knowledge transfer (Rubenstein \& Geisler, 2003). Organizational leaders need to purposely strive to foster a knowledge-sharing culture as a result of these types of counter-productive obstacles. Bartlett and Wozny (2002) indicated that it is important to convey the need to embrace the sharing of knowledge and expertise which incorporates the transferring of best practices, if organizational leaders expect to leverage performance and maintain a competitive advantage. 
The purpose of this study was to determine the perceived effect of downsizing on knowledge sharing. I explored surviving employee perceptions of intra-organizational knowledge sharing in a recently downsized management consultant organization. I used survivor syndrome, as characterized by Noer (1993), and the theory of reasoned action, as outlined by Fishbein and Ajzen (1975) to assess the effects of leveraging knowledge management in recently downsized organizations.

The sharing and creation of knowledge is dependent upon social relationships (Ipe, 2003). An aspect of Fishbein and Ajzen's (1975) theory of reasoned action can be instrumental in creating an environment that promotes learning and the sharing of knowledge. The core concept of the theory centers on an individual's intention to perform a specific behavior. Engaging in the act of knowledge sharing is in turn, determined by the attitude toward, and the subjective norm of a behavior, which can be influenced by organizational ideals relative to fostering a knowledge sharing culture.

The effects of survivor syndrome can result in negative behavioral or attitudinal issues involving feelings of anger, resentment, cynicism, low morale, sabotage, conflict, and other inefficient, non-productive dysfunctional behaviors (Baruch \& Hind, 1999). During the planning phases of many organizational restructurings, attention is given to caring for the employees who will be affected as a result of downsizing efforts (Baruch \& Hind, 1999). This can be accomplished with outplacement vendors bought on board to ensure that the exit process is managed as smoothly as possible. What is missing is that same level of care and attention and/or counseling for the employees who will be left behind to contend with survivor's syndrome (Baruch \& Hind, 1999).

\section{Method}

A quantitative correlation research design was used to investigate three research questions:

1) What is the correlation between survivor syndrome and actual knowledge sharing behavior?

2) What is the correlation between survivors' attitudes toward knowledge sharing and actual knowledge sharing behavior?

3) What is the correlation between perceived loss of knowledge power and actual knowledge sharing behavior?

In an effort to answer the three research questions, three hypotheses were tested to assess survivors' perspective of the effect of downsizing on knowledge sharing. Hypotheses were tested using Spearman's rank-order correlation coefficient. A two-tailed significance of $p<0.01$ was used to conduct the statistical analyses. In an effort to support the research questions and test the hypotheses related to this research study, a survey was used to collect the data. A survey was developed by combining questions and measures that have been validated from previous research studies (Ford, 2004; Kankanhalli et al., 2005; Leung \& Chang, 2002; Sitlington, 2008). The survey included a series of questions designed to measure the three sets of two variables: 1) survivor syndrome and actual knowledge sharing behavior, 2) survivors' attitudes toward knowledge sharing and actual knowledge sharing behavior, and 3) perceived loss of knowledge power and actual knowledge sharing behavior.

The items measuring attitude toward knowledge sharing were based on 13 attitude questions from Ford's (2004) research, where Cronbach's alpha value was .91. The items measuring perceived loss of knowledge power were based on eight questions from Kankanhalli et al., (2005) research. Cronbach's alpha value was .95 . The items measuring survivor syndrome was based on nine questions from Leung and Chang's (2002) research. Cronbach's alpha value was 0.94. The items measuring knowledge sharing behaviors was based on six questions from Sitlington's (2008) research. Cronbach's alpha value was 0.93 . The scales that were used to measure each construct were based on a five-point Likert scale from strongly disagree to strongly agree.

This research study was localized and only generalizable to the management consultant company that participated in the study. As a result, a convenience sample was conducted, consisting of 30 management employees in the Texas region of the organization. In an effort to reach the targeted number of 30 participants, oversampling was done. A total of 50 management-level employees were invited to participate in the study; 41 participants responded. 4 participants had incomplete responses and were not included in the results. As a result the total sample size consisted of 37 participants. Once the survey closed, and data collection ended, data was imported into SPSS, which was the analytical tool used to compute descriptive statistics such as means and standard deviations. Reliability and correlation statistics were computed as well.

\section{Results}

The researcher sought answers to the following research questions:

Research Question 1: What is the correlation between survivor syndrome and actual knowledge sharing behavior?

Null Hypothesis One predicted that there is no correlation between survivor syndrome and actual knowledge sharing behavior. To test this hypothesis, a Spearman correlation was performed (Table 4). Data from the management consultant survivors $(\mathrm{N}=37)$ for the survivor syndrome score were correlated with the actual knowledge sharing behavior data. Lower scores indicate a management consultant survivor who rarely encountered feelings of survivor syndrome or issues with actual knowledge sharing behavior; high scores indicate a management consultant survivor who did encounter feelings of survivor syndrome and issues with actual knowledge sharing behavior. Table 1 displays the correlation results and $p$-value.

The correlation was not significant: $\mathbf{r}_{\mathrm{s}}=-.24, p=.16$. As a result, Null Hypothesis One was not rejected, as findings conclude that there is no correlation between survivor syndrome and actual knowledge sharing behavior among survivors at a management consultant organization.

Research Question 2: What is the correlation between survivors' attitudes towards knowledge sharing and actual knowledge sharing behavior?

Null Hypothesis Two predicted that there is no correlation between survivors' attitudes toward knowledge sharing and actual knowledge sharing behavior. To test this hypothesis, a Spearman correlation was performed (Table 4). Data from the

Table 1.

Spearman's rho between survivor syndrome and actual knowledge sharing behavior.

\begin{tabular}{cccc}
\hline Scale & $\mathrm{N}$ & Actual knowledge sharing behavior & $p$-value \\
\hline Survivor syndrome & 37 & -.237 & .16 \\
\hline
\end{tabular}


management consultant survivors $(\mathrm{N}=37)$ for the attitude towards knowledge sharing score were correlated with the actual knowledge sharing behavior data. Lower scores indicate a management consultant survivor with a negative attitude towards knowledge sharing behavior; high scores indicate a management consultant survivor with a positive attitude towards knowledge sharing and actual knowledge sharing behavior. Table 2 displays the correlation results and $p$-value.

A significant correlation was found: $\mathbf{r}_{\mathrm{s}}=.52, p=.001$. As a result, Null Hypothesis Two was rejected, as findings conclude that there is a positive correlation between survivors' attitudes towards knowledge sharing and actual knowledge sharing behavior among survivors at a management consultant organization.

Research Question 3: What is the correlation between perceived loss of knowledge power and actual knowledge sharing behavior?

Null Hypothesis Three predicted that there is no correlation between perceived loss of knowledge power and actual knowledge sharing behavior. To test this hypothesis, a Spearman correlation was performed (Table 4). Data from the management consultant survivors $(\mathrm{N}=37)$ for the perceived loss of knowledge power score were correlated with the actual knowledge sharing behavior data. Lower scores indicate a management consultant survivor with a negative perception of loss of knowledge power and actual knowledge sharing behavior; high scores indicate a management consultant survivor with a positive perception of loss of knowledge power and actual knowledge sharing behavior. Table 3 displays the correlation results and $p$-value.

A significant correlation was found: $\mathbf{r}_{\mathrm{s}}=-.46, p=.005$. As a result, Null Hypothesis Three was rejected, as findings conclude that there is a negative correlation between perceived loss of knowledge power and actual knowledge sharing behavior.

Table 2.

Spearman's rho between attitude towards knowledge sharing and actual knowledge sharing behavior.

\begin{tabular}{cccc}
\hline Scale & $\mathrm{N}$ & Actual knowledge sharing behavior & $p$-value \\
\hline $\begin{array}{c}\text { Attitude towards } \\
\text { knowledge sharing }\end{array}$ & 37 & .517 & .001 \\
\hline
\end{tabular}

Table 3.

Spearman's rho between perceived loss of knowledge power and actual knowledge sharing behavior.

\begin{tabular}{cccc}
\hline Scale & $\mathrm{N}$ & Actual knowledge sharing behavior & $p$-value \\
\hline $\begin{array}{c}\text { Perceived loss of } \\
\text { knowledge power }\end{array}$ & 37 & -.456 & .005 \\
\hline
\end{tabular}

Table 4.

Imtercorrelations among the summated scale scores $(\mathrm{N}=37)$.

\begin{tabular}{ccccc}
\hline Sore & 1 & 2 & 3 & 4 \\
\hline 1. Suevivor syndrome & 1.00 & & & \\
2. Actual knowledge sharing behavior & -.24 & 1.00 & & \\
3. Perceived loss of knowledge power & .27 & $-.46^{* * * *}$ & 1.00 & \\
4. Atttitudes towords knowledge sharing & $-.31^{*}$ & $.52^{* * * *}-.58^{* * * *}$ & 1.00 \\
\hline Note: ${ }^{*} p<.10 .{ }^{* *} p<.05 .{ }^{* * *} p<.01 .^{* * *} p<.005 .{ }^{* * * * *} p<.001$. & &
\end{tabular}

\section{Discussion}

Organizational downsizing can potentially threaten an organization's performance and productivity; as a result of competent employees who often leave an organization and take years of knowledge with them. Employees in recently downsized organizations often have to contend with a culture in which the mindset centers on the fact that knowledge is power, meaning information is only shared, on a need-to-know basis. As a result, this can lead to knowledge silos being embedded throughout an organization (Rubenstein \& Geisler, 2003).

During the planning phases of many organizational restructurings, attention is given to caring for the employees who will be affected as a result of downsizing efforts (Baruch \& Hind, 1999). This can be accomplished with outplacement vendors bought on board to ensure that the exit process is managed as smoothly as possible. What is missing is that same level of care and attention and/or counseling for the employees who will be left behind to contend with survivor's syndrome (Baruch \& Hind, 1999).

Addressing the morale of survivors is typically not factored into the pre or post downsizing planning process. As a result, they are typically not afforded training and/or counseling opportunities to assist them with managing the emotional and/or psychological issues they may be encountering. Overlooking the wellbeing of survivors could potentially hinder the flow of organizational communication, and in turn, negatively affect the overall knowledge management process (Lesser \& Prusak, 2001).

Beagrie (2005) indicated that because employees who are no longer motivated to work hard can have a toxic effect on a work environment, key managerial skills will be required, in an effort to re-ignite employee passion. This is a time period when organizational leaders actually expect increased involvement and commitment, in hopes that employees will work harder and more competitively in an effort to keep their jobs. While this may be the case initially, it is short-lived and typically followed by malicious behavior within the organization (Appelbaum et al., 1999). As a result, a concerted effort to improve organizational morale must consist of an ability to recognize the symptoms of organizational stress: constant complaining, tense silence, angry explosions, mistakes, avoidance, and turnover (Pater, 2001).

$\mathrm{Lu}$ et al. (2006) indicated that "in knowledge-intensive industries, firms cannot compete if their employees guard their insights as personal secrets" (p. 15). To counter these challenges, Lu et al. (2006) asserted that "[in] [order] to succeed in a knowledge economy, organizations need to develop systematic processes to create and leverage knowledge" (p. 15). The statistical findings of this study provided no support for a correlation between survivor syndrome and actual knowledge sharing behavior; however, results revealed a statistically significant positive correlation between survivors' attitude toward knowledge sharing and actual knowledge sharing behavior. Results also reflected a statistically significant positive correlation between perceived loss of knowledge power and actual knowledge sharing behavior. This research has added to the body of knowledge as a result of the empirical evidence which supports the relationship between downsizing and actual knowledge sharing behavior.

\section{Conclusion}

In general, results suggested that as survivors adjust to mul- 
tiple rounds of layoffs, survivor syndrome is not as prevalent; therefore, there is no relationship between survivor syndrome and knowledge sharing. Results also suggested that if survivors have a positive disposition relative to their attitude towards knowledge sharing, they will share their knowledge. Results also revealed that the more survivors perceive that they are losing their knowledge power, the less they are willing to share their knowledge.

These finding are significant as a result of the potential to increase awareness for survivors and organizational leaders as it relates to the planning phases of organizational restructurings. Findings from this study may also assist with ensuring the proper level of attention and/or counseling is provided for the employees who will be left behind to contend with survivor's syndrome. In the end, the results of this study will also provide organizational leaders with an increased awareness of the problem of knowledge hoarding among survivors in recently downsized organizations.

A key recommendation for action based on this study's findings is for organizational leaders to implement training programs for organizational leaders and survivors to attend, based on the information revealed regarding survivors' perspectives of the challenges often encountered as it relates to knowledge sharing in recently downsized organizations. Training programs should be designed to focus on acknowledging the symptoms survivors may be currently experiencing, or have previously experienced, and provide guidelines on how to better manage and overcome survivor syndrome.

The work of other researchers supports this recommendation, as other researchers have posited that in an effort to counter the negative effects of downsizing, organizational leaders need to take action by focusing on the development of close working relationships, and on providing the support survivors need in order to embrace the sharing of knowledge and expertise and achieve organizational goals (Bartlett \& Wozny, 2002; Lee \& Choi, 2003; Rubenstein \& Gesiler, 2003). Similarly, Ajzen and Fishbein (1980) posited that "an acknowledgement and awareness of what employees' value can be instrumental in rallying employees faced with overcoming survivor's syndrome. When working within the realms of a downsized work environment, it is essential that employees work together and collaborate with other cross functional teams, so that knowledge transfer can take place" (p. 172).

Additional recommendations include the need for managers to also hold focus group meetings with survivors in an effort to identify and assess the organization's overall knowledge management needs. Additionally, if organizational leaders can identify survivors' attitudes towards knowledge-sharing, this will position them to implement the necessary measures needed to assist with improving those attitudes.

This recommendation for action is supported by the findings of this study, and is also supported by the work of other researchers who have posited that "successful downsizing must consist of conducting a knowledge audit of a company's work force" (Managing Successful Downsizing”, 2002: p. 21). Similarly, Fisher and White (1997) asserted that "successful downsizing requires the identification of the formal and informal networks operating in an organization that are essential to its learning capacity since both organizational learning and downsizing can lead to a better competitive position" (p. 458).

The final recommendation for action is to encourage organizational leaders from the very top levels of management, down to the lower levels of management, to focus on fostering a culture that encourages knowledge sharing within newly restructured work environments. Conducting regularly scheduled town hall meetings or team meetings can assist with this effort. This recommendation for action is supported by the findings of this study, and is also supported by the work of other researchers who have posited that leaders should be encouraged to focus on the fact that a major cultural shift is needed to change survivors' behaviors, particularly in organizations faced with having to manage the emotional and workplace needs of survivors whose productivity and morale have been diminished as a result of multiple downsizings (Bhattacharyya \& Chatterjee, 2005).

Baltazar (2001) indicated that the continued trend of massive organizational layoffs has resulted in the need for organizational leaders to place more emphasis on ensuring effective knowledge management practices are in place. Similarly, the research conducted by $\mathrm{Lu}$ et al. (2006), revealed that "at the organizational level, organizational support leads to higher utilization of information and communication technologies, resulting in more knowledge sharing" (p. 35). Additionally, Gibbert and Krause (2002) indicated that while organizations cannot force employees to share knowledge; they can encourage employees to engage in the process. Additionally, Wright (1998) indicated the following:

As organizations continue to evolve into knowledge intensive environments, organizational leaders will need to shift their focus towards the encouragement of knowledge sharing. Knowledge, long regarded as power, has naturally been viewed as ripe for hoarding and in a competitively individualistic environment, sharing it has looked abnormal. As a result, now that organizations are discovering that sharing knowledge makes sound business sense, changing that behavior suddenly looks profoundly connected to their bottom-line fortunes (p. 4).

Based on this study's findings, organizational leaders can implement training programs based on the information revealed regarding survivors' perspectives of the challenges often encountered as it relates to knowledge sharing in recently downsized organizations. A three-fold training approach can be structured, designed, and implemented as follows:

1) Introduction/Overview: Define and acknowledge the current or past existence of survivor syndrome; provide survivors with a brief survivor syndrome assessment test; provide guidelines on how to effectively manage survivor syndrome (Bartlett \& Wozny, 2002; Lee \& Choi, 2003; Rubenstein \& Gesiler, 2003).

2) Analysis/Reflection: Identify and assess the organization's overall knowledge management needs; identify survivors' attitudes toward knowledge sharing; divide the survivors into focus groups and appoint one senior leader to serve as the spokesperson for each group; have survivors brainstorm with their appointed senior leader regarding the overall knowledge management needs of the business and share their personal views regarding their attitudes towards knowledge sharing ("Managing Successful Downsizing", 2002).

3) Goal Setting/Action Plan: Foster a knowledge sharing culture; bring the teams back together as one group to provide a read-out regarding the results in item 2; provide flip charts to be used by the appointed senior leaders to journal survivors' ideas of how their organization can foster a knowledge sharing culture (Lu et al., 2006).

Organizational leaders can apply the findings from this study to assist with designing a survivor training program. The sam- 
ple training outline above can be used as a guide to design the program, which can be implemented to assist with countering the challenges that survivors and leaders often contend with, as it relates to leveraging knowledge management in recently downsized organizations. A potential title for the training program could be: It starts at the Top: Survivor Syndrome \& Knowledge Management Assessment Training.

\section{REFERENCES}

Ajzen, I., \& Fishbein, M. (1980). Understanding attitudes and predicting social behavior. Englewood Cliffs, NJ: Prentice-Hall.

Appelbaum, S. H., Close, T. G., \& Klasa, S. (1999). Downsizing: An examination of some successes and more failures. Management Decision, 37, 424-436. doi:10.1108/00251749910274207

Baltazar, H. (2001). Knowledge management has a human side. eWeek, $18,74-79$.

http://eweek.com/c/a/IT-Management/Knowledge-Management-Hasa-Human-Side

Bartlett, C. A., \& Wozny, M. (2002). GE's two-decade transformation: Jack Welch's leadership. Allston, MA: Harvard Business School. http://hbr.org//product/ge-s-two-decade-transformation-jack-welch-sleader

Baruch, Y., \& Hind, P. (1999). Perpetual motion in organizations: Effective management and the impact of the new psychological contracts on "survivor syndrome". European Journal of Work and Organizational Psychology, 8, 295-306. doi:10.1080/135943299398375

Beagrie, S. (2005). How to manage demotivated employees. Personnel Today, 31-32.

http://business.highbeam.com/410665/article-1G1-138757296

Bhattacharya, S., \& Chatterjee, L. (2005). Organizational downsizing: From concepts to practices. The Journal for Decision Makers, 30, 65-78.

http://vikalpa.com/pdf/articles/2005/2005_july_sep_65_78.pdf

Davenport, T. H., \& Prusak, L. (2000). Working knowledge: How organizations manage what they know (pp. 1-7). Boston, MA: Harvard Business School Press.

http://wang.ist.psu.edu/course/05/IST597/papers/Davenport_know.p df

Fishbein, M. \& Ajzen, I. (1975). Belief, attitude, intention, and behavior: An introduction to theory and research. Reading, MA: Addison-Wesley.

Fisher, S. R., \& White, M. A. (1997). Downsizing and organizational learning: A question of compatibility. Academy of Management Proceedings, 25, 454-458. doi:10.5465/AMBPP.1997.4989390

Ford, D. P. (2004). Knowledge sharing: Seeking to understand intentions and actual sharing. (Doctoral dissertation, University at Kingston, 2004). Dissertation Abstracts International, 66, 536.
Gibbert, M., \& Krause, H. (2002). Practice exchange in a best practice marketplace. In T. H. Davenport, \& G. J. B. Probst (Eds.), Knowledge Management Case Book: Siemens Best Practices (pp. 89-105). Erlangen: Publicis Corporate Publishing.

Henkoff, R. (1994). Getting beyond downsizing. Fortune, 129, 58-64. http://money.conn.com/magazines/fortune/fortune_archive/1994/01/ 10/78843/index.htm

Ipe, M. (2003). Knowledge sharing in organizations: A conceptual framework. Human Resource Development Review, 2, 337-359. doi: $10.1177 / 1534484303257985$

Kankanhalli, A., Tan, B., \& Wei, K. (2005). Contributing knowledge to electronic knowledge repositories: An empirical investigation. MIS Quarterly, 20, 113-143.

http://web.ebscohost.com.ezp.waldenulibrary.org

Lee, H. \& Choi, B. (2003). Knowledge management enablers, processes, and organizational performance: An integrative view and empirical examination. Journal of Management Information Systems, 20, 179-288. http://web.ebscohost.com.ezp.waldenulibrary.org

Lesser, E. \& Prusak, L. (2001). Preserving knowledge in an uncertain world. MIT Sloan Management Review, 43, 101-102. http://web.ebscohost.com.ezp.waldenulibrary.org

Leung, A. S. M., \& Chang, L. M. K. (2002). Organizational downsizing: Psychological impact on surviving managers in Hong Kong. Asia Pacific Business Review, 8, 76-94. doi:10.1080/713999149

Linn, A. (2012). Who's announced most job cuts: Uncle Sam? URL (last checked 29 May 2012).

http://bottomline.msnbc.msn.com/_news/2012/02/13/10376217-whos -announced-most-job-cuts-uncle-sam

Lu, L., Leung, K., \& Koch, P. (2006). Managerial knowledge sharing: The role of individual, interpersonal, and organizational factors. Management and Organization Review, 2, 15-41. doi:10.1111/j.1740-8784.2006.00029.x

Managing successful downsizing. (2002). Corporate Finance, 208, 21-22.

Noer, D. M. (1993). Healing the wounds: Overcoming the trauma of layoffs and revitalizing downsized organizations. San Francisco, CA: Josssey Bass.

Pater, R. (2001). Boosting performance in these changing and pressured times. American Salesman, 46, 10-16. http://allbusiness.com/human-resources/workforce-management/808 430-1.html

Rubenstein, A., \& Geisler, E. (2003). Installing and managing knowledge management systems. Hartford, CT: Greenwood.

Sitlington, H. (2008). Impact of downsizing, restructuring, and knowledge sharing on retention of knowledge in organizations: Implications for organizational effectiveness. URL (last checked 18 January 2009). http://espace.library.curtin.edu.au

Wright, P. (1998). Toward a unifying framework for exploring fit and flexibility in strategic human resource management. Academic Management Review, 23, 756-772. 